Viana et al., Revista Brasileira de Higiene e Sanidade Animal (v.1, n.2) p. 1 - 13, jul - dez (2007)

http://dx.doi.org/10.5935/1981-2965.20070006

Artigo Cientifico

www.higieneanimal.ufc.br

Medicina Veterinária

\title{
Contribuição ao Diagnóstico Diferencial entre Peste Suína Clássica (PSC) e Salmonelose: Análise Patológica revela lesões-chave para determinação etiológica ${ }^{1}$
}

Contribuição ao Diagnóstico Diferencial entre Peste Suína Clássica (PSC) e Salmonelose: Análise Patológica revela lesões-chave para determinação etiológica ${ }^{l}$

Daniel de Araújo Viana ${ }^{2}$, Ana Carolina Landim Pacheco ${ }^{5}$, Jackson Lopes Chagas ${ }^{7}$, Paulo Roberto de Lima Carvalho ${ }^{5}$, Nilo Batista Diniz ${ }^{6}$, Antônio de Pádua Lima ${ }^{4}$, Diana Magalhães de Oliveira $*^{3}$.

2, 3, 4, 5, 6 e 7 Universidade Estadual do Ceará UECE

Resumo: O diagnóstico preciso de enfermidades infecciosas pode se tornar difícil, quando o quadro clínico-patológico das possíveis doenças é confuso, como no caso da Peste Suína Clássica (PSC) e da Salmonelose. A PSC é uma das principais viroses que ocorrem no país sobre forma enzoótica, enquanto a Salmonelose é uma doença bacteriana causadora de diarréia aguda ou crônica e morte em várias espécies animais e seres humanos. Em suínos com enfermidades de evolução aguda e envolvimento de severas lesões gastrintestinais, deve-se realizar o diagnóstico diferencial entre PSC e a Salmonelose. Tal diagnóstico diferencial deve incluir a associação entre anamnese e exame clínico, exames laboratoriais complementares e necroscópicos, já que as duas enfermidades podem ocorrer simultaneamente e seu quadro clínico-patológico pode ser tão semelhante que em geral é necessário um exame laboratorial para identificação. No presente caso, o exame post mortem de um suíno suspeito foi efetuado para avaliação macroscópica de lesões. Fragmentos de órgãos foram coletados para análise histopatológica de rotina e para fazer a correlação com as alterações observadas ao exame necroscópico. Houve coleta de material para exame microbiológico e tentativa de isolamento do agente etiológico. Considerando o quadro anátomo-histopatológico das lesões encontradas neste suíno, e a suspeita clínica de PSC ou 
Viana et al., Revista Brasileira de Higiene e Sanidade Animal (v.1, n.2) p. 1 - 13, jul - dez (2007)

Salmonelose, foi possível fazer uma detalhada análise comparativa das lesões encontradas (macro e microscópicas), as quais, perfeitamente compatíveis com o resultado sorológico negativo para PSC, foram consistentes para a conclusão do diagnóstico como sendo Salmonelose.

Palavras-chave: histopatologia, bacterioses, doenças de suínos

Summary: Accuracy in the diagnosis of infectious diseases in animals might be difficult to achieve when the clinical and pathological outlines are confusing, as it happens with Classical Swine Fever (CSF) and Salmonelosis. CSF is one of the most important viral diseases with an enzootic occurrence in Brazil, while Salmonelosis is a bacterial disease that causes acute or chronic diarrhea and leads to death in several species including man. In pigs with acute developing illnesses that involves severe lesions at stomach and guts, the differential diagnosis must be made between CSF and Salmonelosis. Such differential diagnosis might be made through an association between anamnesis and a detailed clinical examination with laboratorial profiles or post mortem exam, since the two diseases can occur simultaneously and their clinical and pathological outlines are so similar which imposes a microbiology identification of the agent. In the present case, a post mortem examination was accomplished for macroscopic evaluation of lesions. Pieces of organs were collected for routine histological analysis and correlation with those lesions seen in the necropsy. Samples were collected for microbiological exams in attempt to isolate the pathogen. Considering the anatomopathological scene of lesions encountered in this swine and the suspected clinical evidence of CSF and Salmonelosis, we did proceed a detailed comparative analysis of macroscopic and histopathological findings, which in accordance with serological analyses, allowed us to conclude the diagnosis as Salmonelosis.

Key words: histopathology, bacterial diseases, swine diseases

Autor para correspondência - *diana.magalhaes.uece.br Recebido 20/02/2007; Aceito 28/08/2007 
Viana et al., Revista Brasileira de Higiene e Sanidade Animal (v.1, n.2) p. 1 - 13, jul - dez (2007)

\section{Introdução}

Doenças de curso agudo constituem um sério problema para a Suinocultura brasileira. Os prejuízos econômicos decorrentes da mortalidade dos animais acometidos por doenças infecciosas são bastante expressivos e muitas vezes o diagnóstico preciso é difícil, pois o quadro clínico-patológico das doenças pode ser confuso. A Peste Suína Clássica (PSC) é uma virose altamente infecciosa e contagiosa causada por um RNA vírus da família Togaviridae, gênero Pestivirus. Segundo BERSANO et al. (1985) teria sido relatado por Lacerda o primeiro caso da enfermidade no Brasil em 1899, no estado de Minas Gerais, em suínos provenientes do estado de São Paulo e a comprovação e primeiras descrições foram feitas por PENHA (1934) no mesmo estado. A PSC atinge suínos de todas as idades e raças e se caracteriza, na forma aguda, por um quadro hemorrágico e por elevadas morbidade e mortalidade (90 a 100\%) (CORRÊA, 1992; SOBESTIANSKY, 1982). A espécie humana não se infecta pelo vírus da PSC, cuja principal forma de transmissão é o contágio direto. A enfermidade já foi responsável por surtos epizoóticos em todo o país, entretanto, com a adoção de medidas para impedir a introdução de doenças em uma criação, as perdas econômicas foram consideravelmente reduzidas em muitos países, inclusive no Brasil, tornando menos freqüentes os surtos (MAHNEL et al., 1974). Ainda assim, de maneira semelhante à febre aftosa, a PSC é uma das principais doenças que ocorrem no país sobre forma enzoótica e provoca enormes perdas econômicas devido a sua natureza extremamente contagiosa (SERRÃO et al., 1980). Em enfermidades de evolução aguda, com desenvolvimento de lesões gastrintestinais, deve-se realizar o diagnóstico diferencial entre PSC e a Salmonelose (MAHNEL et al., 1974), 
Viana et al., Revista Brasileira de Higiene e Sanidade Animal (v.1, n.2) p. 1 - 13, jul - dez (2007)

doença bacteriana causadora de diarréia aguda ou crônica e morte em várias espécies animais e seres humanos, primeiramente descrita por SALMON e SMITH (1886), tendo como agente bactérias do gênero Salmonella.

Salmonella sp. são germes aeróbios, móveis e gram-negativos da família das Enterobacteriaceae, compreendendo centenas de serovares (espécies) que são divididos em cinco subgêneros com base nas características bioquímicas, genéticas e filogenéticas. Transmitida por via oral, a doença tem grande importância sanitária, por ser comum nos homens e serem os animais seu principal reservatório. Em medicina veterinária, a Salmonelose pode ocorrer epizoótica - enzoótica ou esporadicamente em todas as espécies de animais domésticos, sendo de alta morbidade e mortalidade. Nos suínos, afeta os jovens mais freqüentemente e de maneira mais grave que os adultos (BERSANO et al., 1985; CARLTON et al., 1998; CORRÊA et al., 1992). Entretanto, é extremamente rara em lactentes provavelmente devido à imunidade lactogênica (WILCOCK, 1978). Os animais adultos têm chance de se tornarem portadores clinicamente normais, exceto se influências debilitantes como infecções viróticas concomitantes, especialmente PSC, deficiências nutricionais e estresse (BLOOD E HENDERSON, 1991).

O diagnóstico de Salmonelose e/ou PSC deve incluir associação entre anamnese e exame clínico, exames laboratoriais complementares e necroscópicos, já que as duas enfermidades podem ocorrer simultaneamente e seu quadro clínicopatológico pode ser tão semelhante que em geral é necessário um exame laboratorial para identificação (BLOOD E HENDERSON, 1991). Isso, entretanto não é conclusivo, pois a presença de um determinado agente, embora sugestivo da presença da 
Viana et al., Revista Brasileira de Higiene e Sanidade Animal (v.1, n.2) p. 1 - 13, jul - dez (2007)

enfermidade, não pode confirmar por si só o diagnóstico, e por isso é necessária cuidadosa investigação para determinar se outra doença está presente ou não. Muitas vezes, bactérias do gênero Salmonella, que invadem secundariamente o animal, são responsabilizadas pelo quadro patológico apresentado por um animal com PSC (SANTOS, 1979). Para o diagnóstico anatomo-patológico é indispensável que se façam várias necropsias para que a conclusão seja tirada de um conjunto de dados (SOBESTIANSKY, 1982), bem como é necessário o isolamento do agente causal para associação com as demais observações e resolução do caso. No presente trabalho são apresentadas e descritas as lesões exibidas por um suíno suspeito de PSC e de Salmonelose cujo diagnóstico histopatológico (ao contrário do que é citado na literatura) foi elucidativo para diferenciar as duas enfermidades.

\section{Material e Métodos}

Numa pequena granja de suínos da região metropolitana de Fortaleza ocorreu mortalidade de $85,7 \%$ (numa produção de 20 animais) em cerca de 15 dias. Dos três animais restantes, um macho adulto da raça Landrace permaneceu na propriedade sem manifestações clínicas da doença. Os dois outros, uma fêmea e um macho de 4 meses de idade, de mesma raça, apresentavam clinicamente anorexia, febre, tremores musculares, prostração, além de diversas áreas de equimose e sufusões pelo corpo, principalmente na região abdominal. O quadro cursava com diarréia sanguinolenta e dispnéia atribuída ao decúbito e locomoção insegura. Um dos animais foi encontrado morto e o exame post mortem foi inviabilizado pelo avançado estado de decomposição. Tendo como principais suspeitas clínicas a PSC e a Salmonelose, o outro espécime foi então sacrificado com intuito diagnóstico. Foi 
Viana et al., Revista Brasileira de Higiene e Sanidade Animal (v.1, n.2) p. 1 - 13, jul - dez (2007)

relatado que, pouco antes do sacrifício,

o animal apresentava estado convulsivo.

O exame post mortem foi efetuado para avaliação macroscópica de lesões (SOBESTIANSKY, 1992) e fragmentos de órgãos foram coletados para análise histopatológica de rotina (JUNQUEIRA \& CARNEIRO, 1999) e correlação com as alterações observadas ao exame necroscópico. Houve coleta de material para exame microbiológico (CORRÊA et al., 1992) e tentativa de isolamento do agente etiológico, além de sorologia para Pestivirus (CORRÊA et al., 1992).

\section{Resultados}

O exame necroscópico externo do animal revelou emaciação com manchas purpúreas e irregulares distribuídas pelo corpo, além de fezes sanguinolentas na região perianal. À abertura do cadáver observou-se intenso edema pulmonar, inclusive com evidenciação do padrão lobular. O coração exibia hipertrofia ventricular bilateral.
Na cavidade abdominal, o trato digestivo mostrava gastroenterite hemorrágica com presença de diversas ulcerações de bordos espessos, elevados e pequeno orifício central profundo que acometia principalmente as porções distais do ceco e cólon. O fígado estava endurecido e aumentado de volume. Linfonodos perihepáticos, peripancreáticos e mesentéricos mostravam aumento de tamanho e pequenos focos de hemorragia. Rins e bexiga apresentavam zonas de congestão nas regiões cortical, medular e mucosa, respectivamente.

A análise histopatológica mostrou moderada depleção linfocitária nos linfonodos, com perda de padrão folicular, histiocitose e necrose em pequenos e múltiplos focos, além de congestão e edema moderados (Figura 1). A enterite era aguda, intensamente exsudativa, com inúmeras lesões murais de padrão ulcerativo do tipo botonoso, de fundo necro-hemorrágico e focos 
Viana et al., Revista Brasileira de Higiene e Sanidade Animal (v.1, n.2) p. 1 - 13, jul - dez (2007)

múltiplos de necrose na submucosa

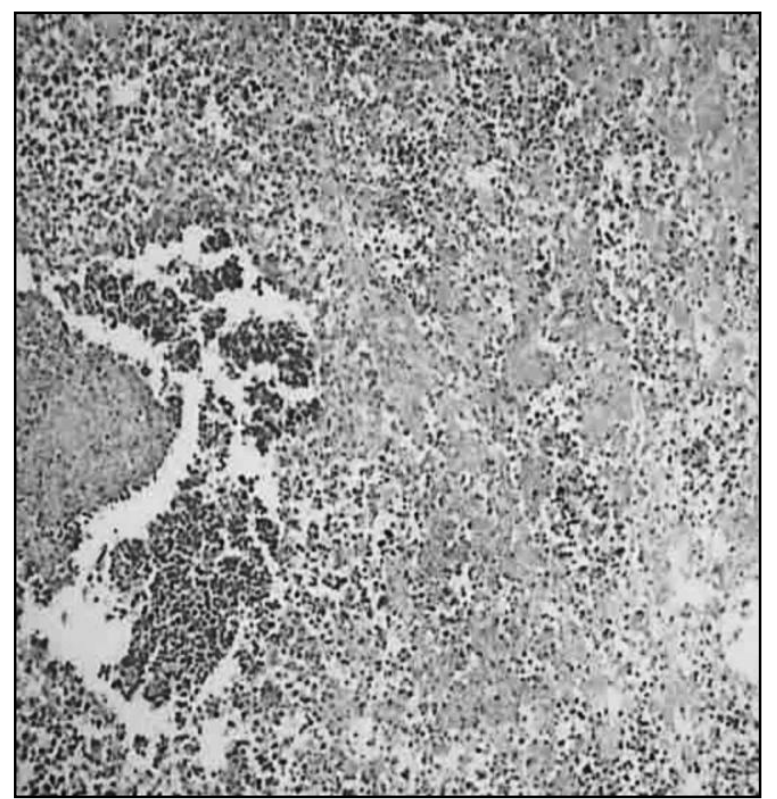

Figura 1 - Histiocitose e necrose em linfonodos mesentéricos - 10X - HE

A broncopneumonite aguda acometia múltiplos lóbulos pulmonares com pequenas zonas de hepatização cinzenta e presença de células gigantes multinucleadas no exsudato. Havia intensa congestão e edema dos septos alveolares e interlobulares (Figura 3). Notava-se edema perivascular e de células endoteliais com marginação linfocitária na pele. Nos rins, havia atrofia glomerular multifocal e em graus variáveis; proliferação mesangial e acúmulo de matriz; além de discreta tumefação turva tubular. A nefrite era
(Figura 2).

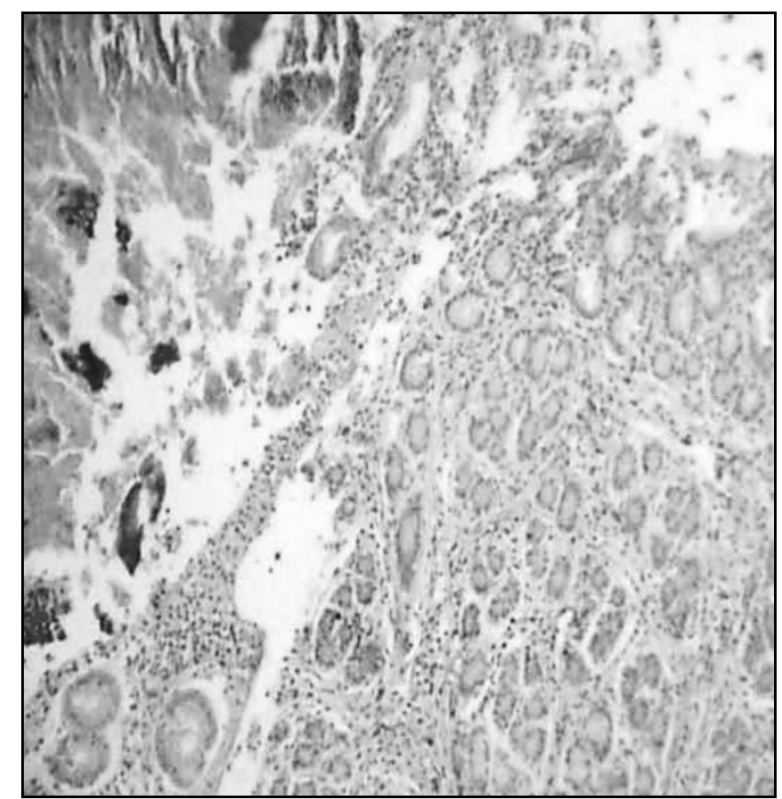

Figura 2 - Enterite aguda e úlcera de aspecto botonoso $10 \mathrm{X}-\mathrm{HE}$

intersticial e se associava com uma pielonefrite moderadamente exsudativa, linfohistiocitária e multifocal. Havia congestão e edema acentuados da zona medular. A bexiga urinária exibia cistite inespecífica, aparentemente acompanhando o padrão visto na pielonefrite, apresentando degeneração balonosa de células transicionais e moderado edema de córion. No fígado havia degeneração hidrópica dos hepatócitos, dilatação e congestão sinusoidal intensa na zona centrolobular, além de exsudação 
Viana et al., Revista Brasileira de Higiene e Sanidade Animal (v.1, n.2) p. 1 - 13, jul - dez (2007)

inflamatória portal linfohistiocitária

(Figura

4). Notava-se destacada

hiperplasia de células de Kupffer.

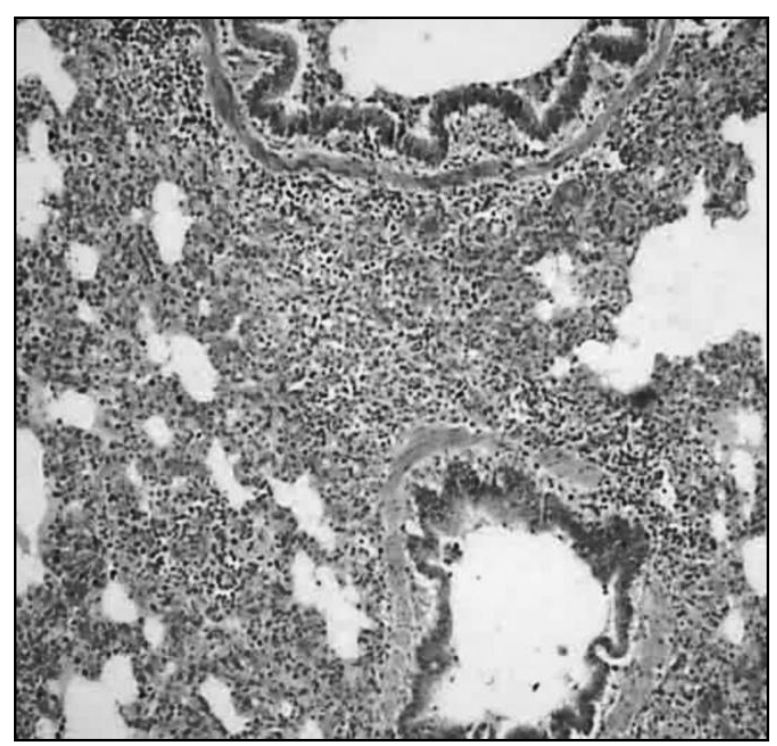

Figura 3 - Broncopneumonia aguda - 10X $-\mathrm{HE}$

Considerando o quadro anatomopatológico das lesões encontradas neste suíno, e a suspeita clínica de PSC ou Salmonelose, foi possível fazer uma análise comparativa dos achados compatíveis com as duas enfermidades no âmbito macroscópico (Tabela 1) e microscópico (Tabela 2), bem como destacar as principais alterações morfológicas encontradas (Tabela 3) e utilizá-las como elementos-
Não houve isolamento de agente bacteriano na cultura e a sorologia para Pestivirus foi negativa.

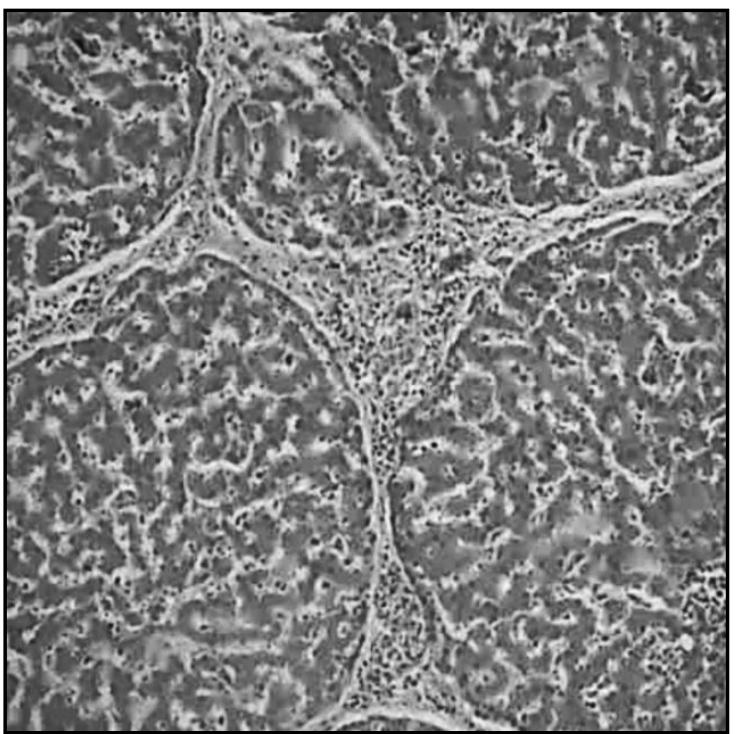

Figura 4 - Hepatite portal linfohistiocitária $-10 \mathrm{X}-\mathrm{HE}$

chave para considerar a Salmonelose como responsável pelo surto.

\section{Discussão e Conclusão}

O diagnóstico diferencial entre PSC e Salmonelose é geralmente conclusivo diante do isolamento do agente etiológico ou sorologia específica (CORRÊA et al., 1992; JONES et al., 2000), sendo que a histopatologia não é tida como capaz 
Viana et al., Revista Brasileira de Higiene e Sanidade Animal (v.1, n.2) p. 1 - 13, jul - dez (2007)

diferenciar as duas enfermidades (CORRÊA et al., 1992).

Tabela 1 - Quadro comparativo entre principais lesões macroscópicas encontradas na PSC e Salmonelose

\begin{tabular}{l|l}
\hline \multicolumn{1}{c|}{ Peste Suína Clássica } & \multicolumn{1}{c}{ Salmonelose } \\
\hline Petéquias e sufusões cutâneas & Petéquias e sufusões cutâneas \\
\hline Pneumonia lobular & Broncopneumonia \\
\hline Hidropericárdio & Congestão cardíaca \\
\hline Hepatomegalia e congestão & Hepatomegalia e congestão \\
\hline Congestão e hemorragia gástricas & Congestão e hemorragia gástricas \\
\hline Enterite catarral/necrótica & Enterite catarral/necrótica \\
\hline Úlceras botonosas intestinais & Úlceras botonosas intestinais \\
\hline Esplenomegalia hemorrágica (infartos) & $\begin{array}{l}\text { Baço congesto com reação de retículo e polpa } \\
\text { branca }\end{array}$ \\
\hline Linfonodos marmorizados/ hemorrágicos & $\begin{array}{l}\text { Linfonodos edematosos e congestos c/ focos de } \\
\text { necrose }\end{array}$ \\
\hline $\begin{array}{l}\text { Síndrome hemorrágica petequial (rins, } \\
\text { serosas, etc.) }\end{array}$ & Hemorragias irregulares \\
\hline
\end{tabular}

\section{Tabela 2 - Contribuição ao diagnóstico histopatológico diferencial entre PSC e Salmonelose}

\begin{tabular}{l|l}
\hline \multicolumn{1}{c|}{ Peste Suína Clássica } & \multicolumn{1}{c}{ Salmonelose } \\
\hline $\begin{array}{l}\text { Pele: degeneração hidrópica, necrose e hemorragia } \\
\text { e marginação leucocitária vascular }\end{array}$ & $\begin{array}{l}\text { Dilatação e congestão de } \\
\text { capilares, microhemorragias }\end{array}$ \\
\hline $\begin{array}{l}\text { Coração: edema e dissociação do sarcoplasma } \\
\text { perinuclear; inclusões virais }\end{array}$ & Congestão e edema vascular \\
\hline $\begin{array}{l}\text { Intestino: infartos, infiltração linfocitária, } \\
\text { espessamento vascular e trombose; necrose e e } \\
\text { ulceração (botonosa) }\end{array}$ & $\begin{array}{l}\text { Infiltração linfohistiocitária com } \\
\text { hiperplasia de folículos linfóides } \\
\text { na lâmina própria; necrose e } \\
\text { ulceração (botonosa) }\end{array}$ \\
\hline $\begin{array}{l}\text { Baço: edema, hialinização e trombose dos vasos; } \\
\text { infartos e petequias nos bordos são } \\
\text { patognomônicos }\end{array}$ & $\begin{array}{l}\text { Congestão e reação proliferativa } \\
\text { de retículo e polpa branca }\end{array}$ \\
\hline $\begin{array}{l}\text { Rins: hemorragias, edema e manguitos } \\
\text { perivasculares de macrófagos e linfócitos; } \\
\text { degeneração epitelial tubular. Glomerulonefrites }\end{array}$ & $\begin{array}{l}\text { Nefrite intersticial e pequenos } \\
\text { focos de necrose }\end{array}$ \\
\hline $\begin{array}{l}\text { Cérebro: congestão e hemorragia dos vasos } \\
\text { sangüíneos }\end{array}$ & Meningoencefalite focal \\
\hline $\begin{array}{l}\text { Linfonodos: degeneração vascular e hemorragias } \\
\text { Fígado: congestão, hemorragias e necrose }\end{array}$ & $\begin{array}{l}\text { Edematosos e congestos c/ focos } \\
\text { de necrose } \\
\text { Nódulos paratíficos e hiperplasia } \\
\text { de células de Kupffer }\end{array}$ \\
\hline
\end{tabular}


Viana et al., Revista Brasileira de Higiene e Sanidade Animal (v.1, n.2) p. 1 - 13, jul - dez (2007)

Tabela 3 - Comparação entre achados de necropsia e histopatológicos encontrados no presente caso e àqueles que seriam encontrados na PSC.

\begin{tabular}{l|ll}
\hline \multicolumn{1}{c|}{ Lesões observadas } & \multicolumn{1}{c}{ PSC } \\
\hline Equimoses e sufusões cutâneas & Equimoses e sufusões cutâneas \\
\hline $\begin{array}{l}\text { Enterite necrótica ulcerativa (úlceras } \\
\text { botonosas) }\end{array}$ & $\begin{array}{l}\text { Enterite necrótica ulcerativa (úlceras } \\
\text { botonosas) }\end{array}$ \\
\hline $\begin{array}{l}\text { Edemaciação e congestão de linfonodos } \\
\text { com áreas de necrose focal }\end{array}$ & $\begin{array}{l}\text { Degeneração vascular e hemorragias em } \\
\text { linfonodos }\end{array}$ \\
\hline $\begin{array}{l}\text { Nódulos paratíficos no fígado e hiperplasia } \\
\text { de células de Kupffer }\end{array}$ & $\begin{array}{l}\text { Congestão, hemorragias e necrose } \\
\text { hepática }\end{array}$ \\
\hline $\begin{array}{l}\text { Congestão e múltiplos focos de necrose nas } \\
\text { demais vísceras }\end{array}$ & Síndrome hemorrágica visceral \\
\hline
\end{tabular}

No presente caso, entretanto, a análise anátomo-histopatológica serviu de apoio diferencial, constituindo forte indicativo da enfermidade responsável pelo surto. A discussão dos achados é feita, por conseguinte, no intuito de fundamentar a relevância das lesões macro- e microscópicas como elementos de discernimento no diagnóstico diferencial das duas doenças.

Achados como a enterite necrótica ulcerativa, edemaciação e congestão de linfonodos com áreas de necrose focal, consideradas características de ambas as enfermidades

(BLOOD

$\&$ HENDERSON,1991; CORRÊA et al., 1992; LEMAN et al., 1992; SANTOS et al., 1979), foram decisivas para o estabelecimento do diagnóstico, uma vez que havia a informação adicional de que o exame sorológico para Pestevírus resultara negativo. Outros achados de necropsia, como o enfartamento do baço e as petéquias hemorrágicas em sua superfície, considerados achados patognomônicos para o diagnóstico de PSC (SOBESTIANSKY, 1992), não foram observados durante o exame post mortem. As úlceras botonosas visualizadas no ceco e cólon dos 
Viana et al., Revista Brasileira de Higiene e Sanidade Animal (v.1, n.2) p. 1 - 13, jul - dez (2007)

animais, embora consideradas

Histologicamente, a presença características de PSC de nódulos paratíficos no fígado e (SOBESTIANSKY, 1992) também hiperplasia de células de Kupffer são podem ser vistas na Salmonelose, o que bastante característicos da infecção por dificulta a análise comparativa, mas Salmonella spp. (LEMAN et al., 1992; que, no presente caso, pôde ser usado de CORRÊA et al., 1992). Na pele, edema forma a concluir o diagnóstico. perivascular e de células endoteliais Conforme vários e clássicos autores com marginação linfocitária são (BLOOD e HENDERSON, 1991; alterações vistas na PSC (CORRÊA et CORRÊA et al., 1992; LEMAN et al., 1992), há dúvidas se tais lesões são causadas pelo vírus da PSC ou pela invasão secundária por Salmonella (BLOOD E HENDERSON, 1991). Pelos resultados aqui descritos, parecenos pertinente comentar alguns aspectos dessas úlceras botonosas tais como a consistência friável que possuem (dada à necrose central exuberante) e como os bordos elevados que circundam o centro das úlceras e dão o aspecto descrito como botonoso observado na Salmonelose. Esses pontos são destacados como válidos na observação diferencial.

al., 1992), contudo, a falta de lesões degenerativas vasculares, evoluindo para a característica síndrome hemorrágica, principalmente petequial (provocada pelo Pestivirus) pode servir como excludente de PSC (SOBESTIANSKY, 1982).

No presente caso, viu-se que a Salmonelose levou à morte os animais da propriedade, fato esse consubstanciado pelos achados anteriormente citados como a hepatite portal constituindo nódulos paratíficos, enterite necrótica formando úlceras botonosas na porção distal do intestino e síndrome congestiva com múltiplos 
Viana et al., Revista Brasileira de Higiene e Sanidade Animal (v.1, n.2) p. 1 - 13, jul - dez (2007)

focos de necrose nas demais vísceras.

Destarte, conclui-se que o substrato

morfológico das lesões observadas

\section{Referências Bibliográficas}

ANDERSON, N. V. et al. Septicemic salmonellosis in two llamas. Journal of the American Veterinary Medical Association 1995 jan 1; 206(1): 75-6

BERSANO, J. G. et al. Diagnóstico precoce de peste suína clássica através de biopsia de amígdalas. Biológico vol. 51(7): 181-184, 1985

BLOOD, D. C.; HENDERSON, J. A. Medicina Veterinária. Rio de Janeiro: Guanabara Koogan, 1991

CARLTON, W. W. \& McGAVIN, M. D. Patologia Veterinária Especial de Thomson. $2^{\mathrm{a}}$ ed. Porto Alegre: Artmed, 1998

CORRÊA, W. M. \& CORRÊA, C. N. $M$. Enfermidades Infecciosas dos Mamíferos Domésticos. $2^{\mathrm{a}}$ ed. São Paulo: Medsi, 1992

COTTEREAU, P. Classical swine fever: diagnosis. Bulletin Office International des Epizooties. 1971 Set-Oct; 75(9): 573-600

HARRINGTON, R. Jr; HULSE, D. C.; BLACKBURN, B. O. Salmonella isolated from swine suspected for having hog cholera. American Journal of Veterinary Reseach 1971 Aug; 32(8): 1297-9

HAVLIK, J.; DVORSKY, K.; SEIDLER, L.; KUBECOVA, D.; JAROS,M. Contribution on Salmonella cholerae suis infection. Deutsche Gesundheitsw. 1966 Nov 17; 21(46): 2182-4 macro - e microscopicamente foi eficiente para determinar a etiologia do surto descrito neste caso.

HESS,J.; KAUFMANN, S. H. Salmonella enterica infection. Research Immunology 1996 Oct-Dec; 147(8-9): 581-6

JONES, T. C.; HUNT, R. D. et al. Patologia Veterinária. $6^{\mathrm{a}} \mathrm{ed}$. São Paulo: Manole, 2000

JUNQUEIRA, L.C.; CARNEIRO, J. A histologia e seus métodos de estudo. In: JUNQUEIRA, L.C.; CARNEIRO, J. Histologia Básica. 9 $9^{a}$ ed. Rio de Janeiro, Brasil: Guanabara Koogan, 1999

LEMAN, A. D.; STRAW, B. E. et al. Diseases of Swine. $7^{\mathrm{a}}$ ed. Iowa, USA: Wolfe, 1992

MELDRUM, K. C. Differential diagnosis of suspected swine fever. Veterinary Records 1993 Jul 24; 133(4): 99

MAHNEL, H. \& MAYR, A. Schweinepest. Stuttgart, Alemanha Oc.; Ferdinand Enke Verlag, 1974. 163p

NAKONECZA, I; HSU, H. S. The comparative histopathology of primary and secondary lesions in murine salmonelosis. Brazilian Journal Experimental Pathology 1980; 61: 7684

NORDSTOGA, K. Porcine salmonellosis. I. Gross and microscopic changes in experimentally infected animals. Acta Veterinaria Scandinavica 1970; 11: 361-369 
PENHA, A. M. Casos de Peste de porcos observados em São Paulo. Arquivos do Instituto Biológico de São Paulo; 5: 137-141, 1934

PRITOULINE, P. I. Diagnosis of swine fever. Bulletin Office International des Epizooties 1971 Sept-Oct; 75(9): 626-36

SALMON, D. E.; SMITH, T. 1986. The bacterium of swine plague. American Mon Microbiology Journal 7: 204

SANTOS, J. A. Patologia Especial dos Animais Domésticos. Rio de Janeiro: Interamericana, 1979

SCHIMIDT, D.; WITTMANN, E.; BERGMANN, H. On the prophylaxis of swine salmonellosis as a condition for the successful use of crystal violet vaccine against hog cholera. Zentralbl Bakteriologie. 1964 Dec; 195(2): 16774

SCHULZE, W.; BICKHARDT, K. The dignosis of hog cholera. Deutsche Tierarztl Wochenschr. 1963 Nov 15; 70(22): 628-33

SOBESTIANSKY, J. Peste Suína Clássica e Africana. São Paulo: Nobel, 1982

WILCOCK, B. P. 1978. Experimental Klebsiella and Salmonella infection in neonatal swine. Canadian Journal of Comparative Medicine 43: 100-106

WOOD, G. N. Disease similar to swine fever. Veterinary Records 1993 Jun 19: 132(25): 640 